\title{
Formulation of Critical Micellar Concentration of Non- Phosphate Detergents by Surface Tension Measurement
}

\author{
*S. Yunusa, I. A. Mohammed-Dabo and A. S. Ahmed \\ Department of Chemical Engineering, Ahmadu Bello University, Zaria, Nigeria \\ [Corresponding Author, E-mail: sImnyunus@gmail.com; 8:+2348038951472]
}

\section{ABSTRACT}

Non-phosphate builders which are environmentally friendly are required for use in detergent formulation to replace the sodium tri-poly phosphate (STPP). Phosphates are excellent fertilizer for algae, bacteria, and other flora and fauna in rivers, lakes and oceans, making them bloom at very rapid rates. This exhausts the oxygen supply both in the surface and in the bottom layers of water bodies, and leading the death of fishes. Sodium metasilicate a non-phosphate builder from Lokoja Quartzite was used to formulate a non-phosphate biodegradable synthetic detergent using $25 \%, 50 \%$ and $75 \%$ sodium hydroxide concentrations. The critical micellar concentration (CMC) of a non-phosphate detergent was determined via measurement of surface tension. This method is rapid, reliable and cheap compared to the fluorescence polarization method which required a sophiscated materials such as 1,6-diphenyl-1,3,5-hexatriene as fluorescence probe. The detergents formulated with $75 \%$ and $50 \%$ sodium hydroxide concentrations have CMC values of $8.6685 \mathrm{mM}$ and $6.9348 \mathrm{mM}$ respectively. From this study, a non phosphate builder synthesized from Lokoja Quartzite has potential of protecting aquatic animals when compared with the conventional STPP currently used in our detergent formulation. Also, the simple and economical approach for determination of detergent's CMC has demonstrated it's potentials. These values agree well with the literature value ranges between 7 to $10 \mathrm{mM}$.

Keywords: Detergent; CMC; Surfactants; Non-phosphate; 1,6-diphenyl-1,3,5-hexatriene

\section{INTRODUCTION}

A detergent is a surfactant or a mixture of surfactants having cleaning property in dilute solutions. Detergent, when dissolved in water, gives it the ability to remove dirt from surfaces such as the human skin, textiles and other solids (Yunusa et al., 2009a). Detergents are commonly available as powders or concentrated solutions (Keshwani et al., 2015). They are classified into three groups namely Anionic, Cataionic and Non-anionic or zwitterionic detergents, depending on the electrical charge of the surfactants (Yangxin et al,. 2008).

The most important property of a detergent is its critical micellar concentration (CMC) (Tschapek et al., 2015). CMC can be defined as the concentration of the detergent in a given solvent at or above which detergent molecules, cluster to form micelles (Gregory et al; 2002). Micelles are spherical groupings of 40 to 100 molecules in which all hydrophobic ends point toward the centre and all hydrophilic ends stick out in the surrounding water. Removal of dirt is facilitated by the ability of the detergent molecules to form these micelles (Gregory et al., 2002). Also, below this CMC, detergent molecules are present as monomers and thus are not able to emulsify and solubilize oil and grease (dirt) (Campbell, 2008). Above the CMC the concentration of free (monomeric) detergent molecules does not further increase, because addition of more detergent results in the formation of micelles as illustrated in Figure 1 (Held, 2014).

Three of the most popular methods used to determine CMC are surface tension, light scattering and dye solubilization (Held, 2014). Surface tension decreases with the detergent concentration and reaches a minimum around the CMC value. Light scattering as well as the solubility of a hydrophobic dye increase with detergent concentration (Thomas et al., 2006). The points of inflection on a graph obtained by plotting any of the three parameters against the detergent concentration correspond to the CMC of the detergent (Held, 2014).

Detergent surfactant Sodium dodecyl sulfate (SDS), $\quad \mathrm{NaOSO} \neg 3 \mathrm{C}_{12} \mathrm{H}_{25}$ is known as amphiphilic surfactant because it possesses both hydrophobic and hydrophilic properties. When SDS is dissolved in distilled water it ionizes in the aqueous solution to form $\mathrm{Na}+$ and $-\mathrm{OSO}\urcorner 3 \mathrm{C}_{12} \mathrm{H}_{25}$ ions and these ions exist as 
solvated monomer instead of micelle due to low SDS concentration (Yangxin et al., 2008). The number of monomers increases as the concentration of the detergent in the solution increases (Tschapek etal., 2015). Selfdissociation of SDS into micelle is strongly cooperative and occurs at the defined concentration called critical micelle concentration (Gregory et al., 2002). Below $\mathrm{CMC}$, the amphiphile dissolves as monomers. Once the concentration is beyond CMC, the monomers concentration remains unchanged while the micelle concentration increases (Keshwani et al., 2015)

Quartzite is a metamorphic rock consisting largely or entirely of quartz. Most quartzites are formed by metamorphism of sandstone. But some have developed by metasomatic introduction of quartz, often accompanied by other chemical elements, for example, metals and sulphur (ore quartzite) (Gutti, 1999).

The geological relations and the shape of quartzite bodies serve to distinguish between them. The metasomatic quartzites are often found as contact products of intrusive bodies (lbrahim, 1995).

The transition from sandstone to quartzite is gradational (Yunusa et al., 2009a). All stages of relic elastic structures are encountered. Some sandstones are soon completely metamorphosed (Barth, 2012). Others are very resistant and in many highly metamorphic quartzite of the Precambrian, there are relic structures still to be observed (Gutti; 1999). Pure sandstone yields pure quartzite. Impure sandstone yields a variety of quartzite types (Gutti, 1999).
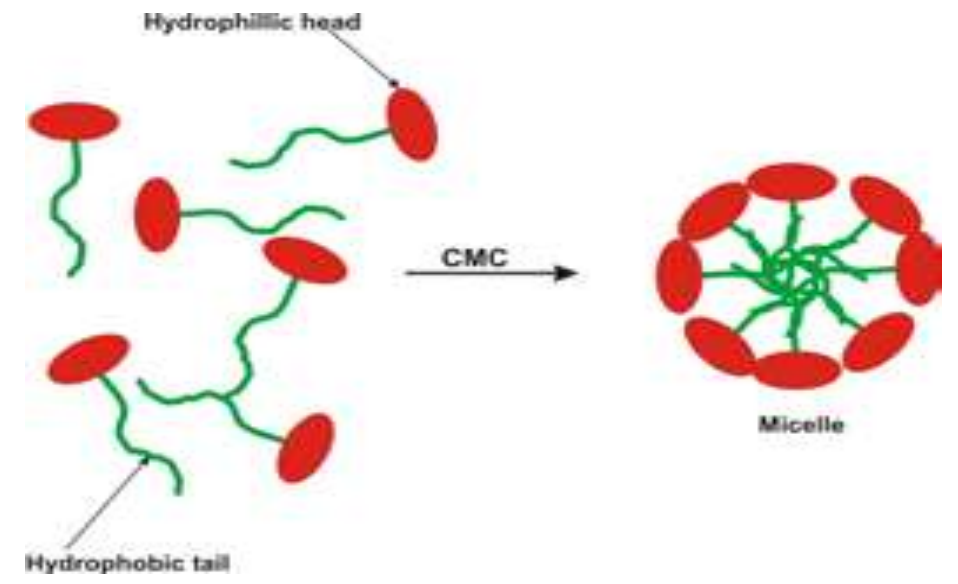

Figure 1: Schematic drawing of Micelle formation (Held, 2014).

\section{MATERIALS AND METHODS \\ Materials}

The Materials used included non-phosphate builder detergent prepared from Lokoja Quartzite, deionized water, the frame which consisted of a copper wire, cotton thread as shown in Figure $2 a$, with the upper thread and the wire labelled $A B C$ and DEF with the shape indicated in Figure $2 b$, retort stand, ruler and a beaker.

\section{Preparation of a non-phosphate Builder from Lokoja Quartzite}

Quartzites were collected from Zagon Daji, a locality of about five kilometers from Lokoja town in Kogi State, Nigeria. The raw quartzite were washed to remove the dust and other dirt on it. The washed quartzite were crushed into 37.5mm mesh using a Jaw Crusher BBI 70992 Shanghai Joyal Machinery Co., Ltd. The crushed quartzite was heated in Electric furnace Nabertherm $\mathrm{GmbH}$, Germany at $800^{\circ} \mathrm{C}$ for 6 hours. This was to make cracks in the quartzite. It also breaks the complex formation, like metal ore attached to it. The calcined quartzite was ground into fine powder, using grinding machine (SIEBTCHNIK GmbH, 
Germany). The finely ground quartzite was sieved through 75,150 and $300 \mu \mathrm{m}$ mesh sieves. The 75, 150 and $300 \mu \mathrm{m}$ mesh sieved quartzite $\left(\mathrm{SiO}_{2}\right)$ and dense form of soda $\left(\mathrm{Na}_{2} \mathrm{CO}_{3}\right)$ were weighed into ratio 1:1 according to equation 2.1 and mixed properly according to (James, 1992).

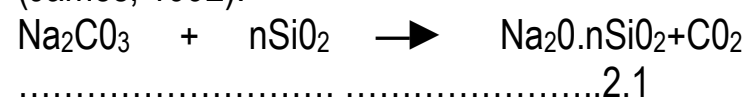

The mass proportions between the reactants is given in equation (2.2)

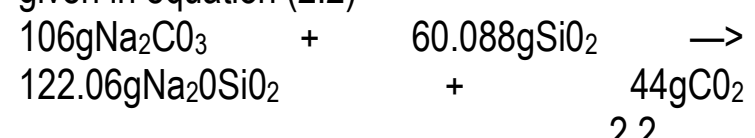

The weighed mixtures were placed into an $\mathrm{LH}$ 120/14 electric furnace Nabertherm $\mathrm{GmbH}$, Germany and was fired at $1000^{\circ} \mathrm{C}, 1050^{\circ} \mathrm{C}$ and $1100^{\circ} \mathrm{C}$ for 10,20 and 30 minutes for quartzite particle sizes of $75 \mu \mathrm{m}, 150 \mu \mathrm{m}$ and $300 \mu \mathrm{m}$ respectively.

The fired samples were removed from the crucibles and crushed, then sieved into $1.2 \mathrm{~mm}$.

After crushing and sieving of the fired samples, they were analyzed. Two methods used for the analysis of soluble silicate were gravimetric for silica $\left(\mathrm{SiO}_{2}\right)$ and atomic absorption spectrophotometer, (AAS) Shimadzu Corporation LTD, Japan, for determining sodium oxide $\left(\mathrm{Na}_{2} \mathrm{O}\right)$ (Yunusa et al., 2009b).

\section{Formulation of Non-Phosphate Biodegradable Detergent.}

This step involved dissolving $50 \mathrm{~g}, 75 \mathrm{~g}$ and $25 \mathrm{~g}$ of sodium hydroxide pellets separately in $50 \mathrm{ml}$ of distilled water and made up to $100 \mathrm{ml}$ in order to get $50 \%, 75 \%$ and $25 \%$ respectively, the solution was stirred continuously to ensure complete dissolution of $\mathrm{NaOH}$ pellets. Each of the prepared sodium hydroxides $(\mathrm{NaOH})$ was used to neutralize the linear alkyl benzene sulfonoate (LABS) to form a neutral detergent paste. The process was controlled by monitoring the $\mathrm{pH}$ value using Kent $7020 \mathrm{pH}$ meter, UK.

The solid additives such as sodium metasilicate, carboxyl methyl cellulose (CMC),

$\frac{h^{2}-d^{2}}{d}=\frac{m g}{2 \gamma}-2 a$ colour etc were mixed in 50wt. \%, 20wt. \%, and IOwt. \% respectively. This was then mixed with $10 \mathrm{wt} . \%$ of water to form slurry. The slurry was then mixed with the neutral detergent paste. The resulting mixture was stirred using a 73660 mechanical stirrer Silverson Machines LTD, England to prevent formation of lumps.

The resulting detergent was dried in an open air with the assistance of a ceiling fan. The dried detergent was then sieved through a $1.2 \mathrm{~mm}$ sieve size into powder. Lemon perfume was added to the powder detergent produced to improve the appearance and to make the washed clothes smell nicely.

\section{Determination of CMC of a non-phosphate detergent}

The CMC of a non-phosphate detergent was determined employing a method of measuring a surface tension of the detergent solution in form of a film as outlined by Konyehi, (2008)

$0.05 \mathrm{~g}$ of detergent was dissolved in a $100 \mathrm{ml}$ of deionized water and the solution stirred. Then the frame was carefully lowered into the solution as shown in Figure 2a. Then the frame was withdrawn and allowed to drain and any films appearing between the upper thread and the wire $A B C$ and $D E F$ were punctured, the thread assumed the shape indicated in Figure $2 b$. Then the measurement of GH, DF and CF were taken with a transparent ruler. The procedure was repeated with weight of 0.00 , $0.45,0.85,1.02$ and $1.20 \mathrm{~g}$ attached at point $\mathrm{E}$ as shown in Figure 2a. This procedure was repeated with detergent concentrations of $0.0005,0.0010,0.0015,0.0020,0.0025$ and $0.0030 \mathrm{ml} / \mathrm{g}$. The values $\mathrm{GH}$ and $\mathrm{CD}$ for each detergent concentration was measured with a ruler, recorded and graph plotted using the relationship in equation 1 . A surface tension was determined from the slope of the graph, for every run, until the surface tension became constant and ceased to decrease with an increase in the concentration of detergent and this point is called critical micelle concentration (CMC).

Where, 


$$
\begin{aligned}
& \mathrm{AC}=\mathrm{DF}=2 \mathrm{a} \\
& \mathrm{GH}=2 \mathrm{~b} \\
& \mathrm{AD}=\mathrm{CF}=2 \mathrm{~h} \\
& \text { slope }=\frac{g}{2 \gamma} \\
& \gamma=\text { surface tension, } \mathrm{g}=9.81 \mathrm{~m} / \mathrm{s}^{2}
\end{aligned}
$$

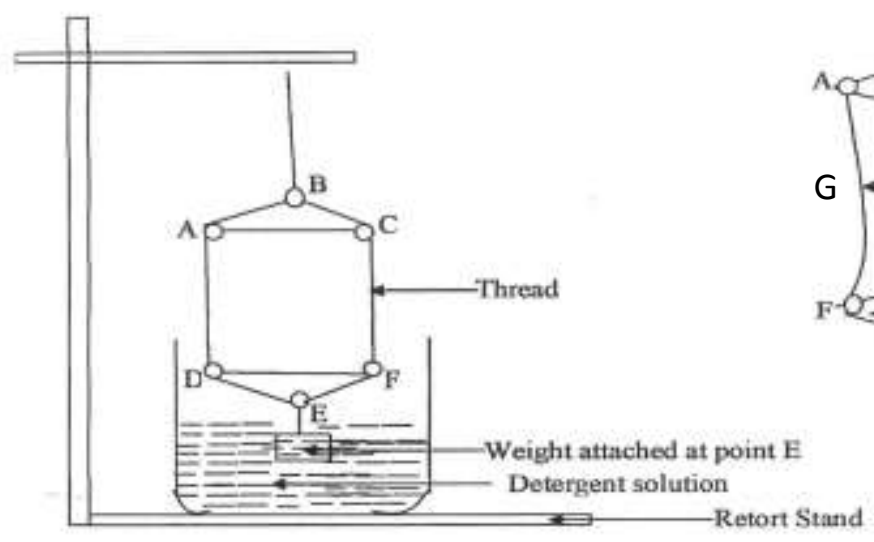

(a)

Figure 2: (a) Experimental set-up for surface tension test (b) Graphical representation of the Film formed in the detergent solution

\section{RESULTS AND DISCUSSION}

Table 3.1 presents the chemical compositions of the produced sodium metasilicate at $1000^{\circ} \mathrm{C}$, while Table 3.2 gives the comparison of chemical compositions of the standard sodium metasilicate to that of the produced sodium metasilicate at $1050^{\circ} \mathrm{C}$ and $1100^{\circ} \mathrm{C}$ at various particle sizes and different times of samples firing. Ratios of oxides of silica to sodium are as well presented. Samples with a quartzite particle size of $75 \mu \mathrm{m}$ when fired at $1000^{\circ} \mathrm{C}$ for 10, 20 and 30 minutes, fused and solidified immediately after it was removed from the furnace. It was bluish in colour. The bluish colour was due to the presence of element such as copper $(\mathrm{Cu})$ in the quartzite and other impurities. Ordinarily, it should be either whitish or colourless (Yunusa et al; 2009b).

The analyzed standard sodium metasilicate is made up of $21.3 \mathrm{wt} . \% \mathrm{SiO}_{2}$ and $23.9 \mathrm{wt} . \% \mathrm{Na}_{2} \mathrm{O}$ (Table 3.2). James (1992) reported the following values for three forms of sodium metasilicate: the sodium metasilicate pentahydrate; $29.3 \mathrm{wt} \% . \quad \mathrm{Na}_{2} \mathrm{O}$ and $26.4 \mathrm{wt} . \%$ $\mathrm{SiO}_{2}$, anhydrous sodium metasilicate, $51 \mathrm{wt} \%$ $\mathrm{Na20}$ wt.\% and 47.1 wt.\% Si02, sodium metasilicate nonahydrate $22-23 \mathrm{wt} . \% \mathrm{Na} 20$ and 19- 21wt.Si02.
When the values obtained for the three forms of sodium metasilicate were compared with the results obtained in Table 3.1 for all process conditions, it can be seen that sodium metasilicate cannot be produced under these conditions. At $1050^{\circ} \mathrm{C}$ and $75 \mu \mathrm{m}$ particle size for 10, 20, 30 minutes the samples fused and solidified with bluish colour.

When the standard and literature values of $\mathrm{SiO}_{2}$ and $\mathrm{Na}_{2} \mathrm{O}$ weight compositions were compared with the results in Table 3.2, it can be seen that only sample fired at $1050^{\circ} \mathrm{C}$ for 20 minutes produced sodium metasilicate nonahydrate for particles of $75 \mu \mathrm{m}$ and $150 \mu \mathrm{m}$ and samples fired at $1050^{\circ} \mathrm{C}$ for 30 minutes sodium silicate anhydrous glasses were formed because James, 1992 reported the values to be 33wt.\% $\mathrm{Na}_{2} \mathrm{O}$ and 66 wt. $\% \mathrm{SiO}_{2}$. While samples fired at $1100^{\circ} \mathrm{C}$ for all particle sizes produced sodium metasilicate because the results agree with James, 1992 for sodium metasilicate nonahydrate.

Figures $3 a, b$ and $c$. shows that there was a steep change of the slope of the graph as detergent concentration increases until concentration of detergent was reached when the slope of the plot remains unchanged which demonstrates that the molecular micelles start to form. As shown by the plots in Figures $3 a, b$ 
and $c$ as the concentration of the detergent increases the slope of the graph also increases until the slope remains unchanged as concentration of detergent further increases. Figure $3 a$ is a plot for $25 \%$ based $\mathrm{NaOH}$ formulated detergent, while Figures $3 \mathrm{~b}$ and $3 \mathrm{c}$ are for $50 \%$ and $75 \% \mathrm{NaOH}$ based formulated detergent at different concentration of the detergents respectively. From the plots, the detergent concentrations at which the slope of the graphs remained unchanged were 0.0025 $\mathrm{g} / \mathrm{ml}, 0.0020 \mathrm{~g} / \mathrm{ml}$ and $0.0015 \mathrm{~g} / \mathrm{ml}$ for $75 \%$, $50 \%, 25 \%$ based $\mathrm{NaOH}$ formulated detergents respectively and the corresponding slope value has about $12.03 \mathrm{~cm} / \mathrm{g}$. The CMC's values were found to be $8.6685 \mathrm{mM}, 6.9348 \mathrm{mM}$ and 5.2011 $\mathrm{mM}$ for $75 \%, 50 \%$ and $25 \%$ based $\mathrm{NaOH}$ formulated detergent respectively.

Comparing these results with the reported values of $7-10 \mathrm{mM}$ by Yunusa et al.,_(2009a). It can be observed that, $75 \%$ and $50 \% \mathrm{NaOH}$ based formulated detergents with the CMC's values of $8.6685 \mathrm{mM}$ and $6.9348 \mathrm{mM}$ agree with literature values, while $25 \%$ based $\mathrm{NaOH}$ formulated detergent with CMC value of 5.2011 $\mathrm{mM}$ does not agree with Yunusa et al.,_2009a) reported values. From the results it can be seen that $75 \% \mathrm{NaOH}$ based detergent has a higher value of $\mathrm{CMC}$ followed by the $50 \% \mathrm{NaOH}$ based detergent, while $25 \% \mathrm{NaOH}$ based detergent has the lowest CMC. This may be due to the fact that both $75 \%$ and $50 \%$ based detergent samples have a lower concentration of surfactant, hence it required a higher concentration detergent before the formation of micelles. Conversely, the $25 \% \mathrm{NaOH}$ based detergent had a higher concentration of surfactant and formed micelles at lower concentration of the detergent. From this study, a non-phosphate builder synthesized from Lokoja Quartzite has potential of protecting an aquatic animals when compared with the conventional STPP currently used in our detergent formulation. Also, the simple and economical approach adopted in this work for determination of detergent's CMC has demonstrated its potentials.

Table 3.1: Composition of the fired Samples of sodium metasilicate produced at $1000^{\circ} \mathrm{C}$

\begin{tabular}{lllllll}
\hline $\mathrm{S} / \mathrm{N}$ & Time $(\mathrm{min})$ & $\begin{array}{l}\text { Particle } \\
\text { Size }(\mu \mathrm{m})\end{array}$ & $\begin{array}{l}\text { Concentration of } \\
\mathrm{Na}(\mathrm{mg} / \mathrm{L})\end{array}$ & $\mathrm{SiO}_{2} \mathrm{wt} . \%$ & $\mathrm{Na}_{2} \mathrm{O}$ wt.\% & $\begin{array}{l}\mathrm{SiO}_{2}: \mathrm{Na}_{2} \mathrm{O} \\
\text { Mole ratio }\end{array}$ \\
\hline 1 & 10 & 75 & 13.9606 & 25.04 & 3.74 & 6.66 \\
& 20 & 75 & 53.7735 & 29.61 & $14 . .5$ & 2.04 \\
& 30 & 75 & 58.3629 & 37.50 & 15.73 & 2.38 \\
2 & 10 & 150 & 0.5960 & 15.24 & 0.16 & 95.30 \\
& 20 & 150 & 24.1063 & 18.07 & 6.50 & 2.78 \\
3 & 30 & 150 & 65.1397 & 29.04 & 17.56 & 1.65 \\
& 10 & 300 & 0.3807 & 13.70 & 0.10 & 137.0 \\
& 20 & 300 & 10.6430 & 24.08 & 2.87 & 8.39 \\
& 30 & 300 & 38.8701 & 26.06 & 10.48 & 2.49 \\
\hline
\end{tabular}

Table 3.2: Composition of the produced and standard sodium metasilicate

\begin{tabular}{llllllll}
\hline S/N & Temp. $\left({ }^{\circ} \mathrm{C}\right)$ & $\begin{array}{l}\text { Time } \\
(\mathrm{min})\end{array}$ & $\begin{array}{l}\text { Particle } \\
\text { Size }(\mu \mathrm{m})\end{array}$ & $\begin{array}{l}\text { Concentration of } \\
\mathrm{Na}(\mathrm{mg} / \mathrm{L})\end{array}$ & $\begin{array}{l}\mathrm{SiO}_{2} \\
\text { wt. \% }\end{array}$ & $\begin{array}{l}\mathrm{Na}_{2} \mathrm{O} \\
\text { wt. \% }\end{array}$ & $\begin{array}{l}\mathrm{SiO}_{2}: \mathrm{Na}_{2} \mathrm{O} \\
\text { mole ratio }\end{array}$ \\
\hline 1 & 1050 & 20 & 75 & 93.3535 & 23.81 & 25.16 & 0.95 \\
2 & 1050 & 20 & 150 & 80.9586 & 20.32 & 21.82 & 0.93 \\
3 & 1100 & 10 & 75 & 84.1038 & 21.10 & 22.67 & 0.93 \\
4 & 1100 & 10 & 150 & 82.6300 & 20.90 & 22.30 & 0.94 \\
5 & 1100 & 10 & 300 & 81.6910 & 20.60 & 22.00 & 0.94 \\
\multicolumn{2}{c}{ STANDARD SODIUM METASILICATE } & & & & \\
6 & - & - & - & 88.9410 & 21.30 & 23.90 & 0.90 \\
\hline
\end{tabular}




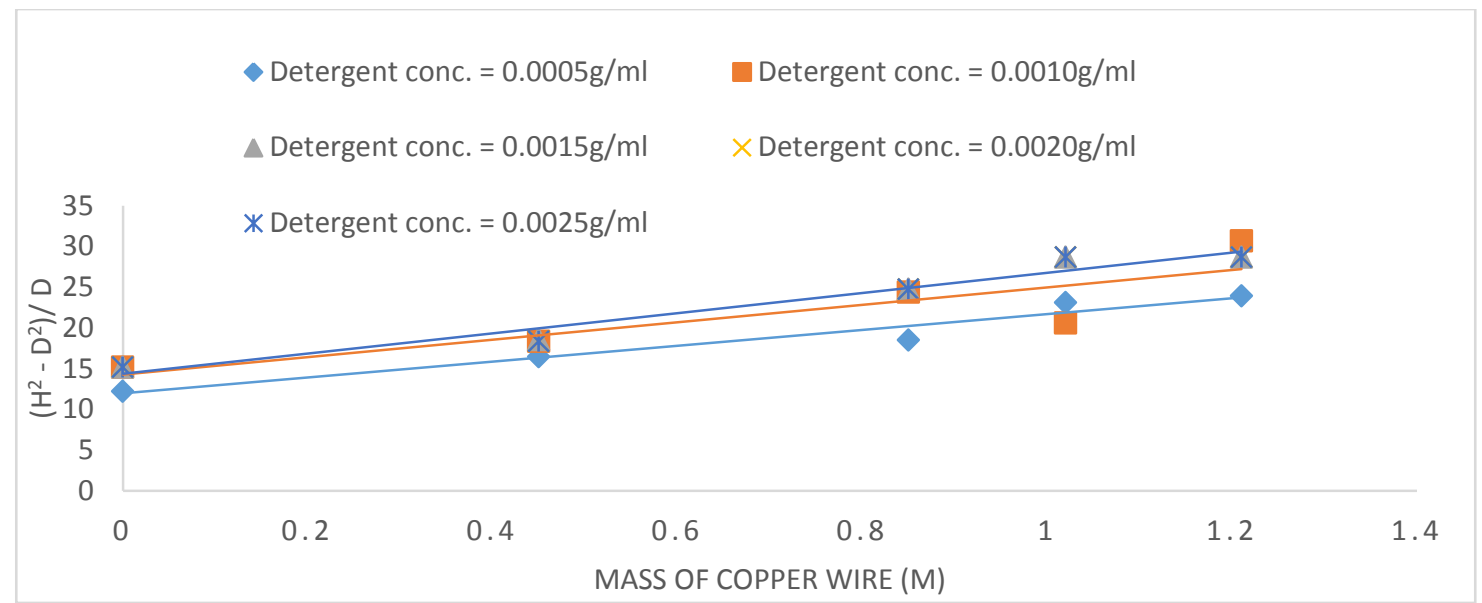

Figure 3a: Determination of CMC's of $25 \% \mathrm{NaoH}$ based Non-phosphate builder Detergent using different detergent concentrations

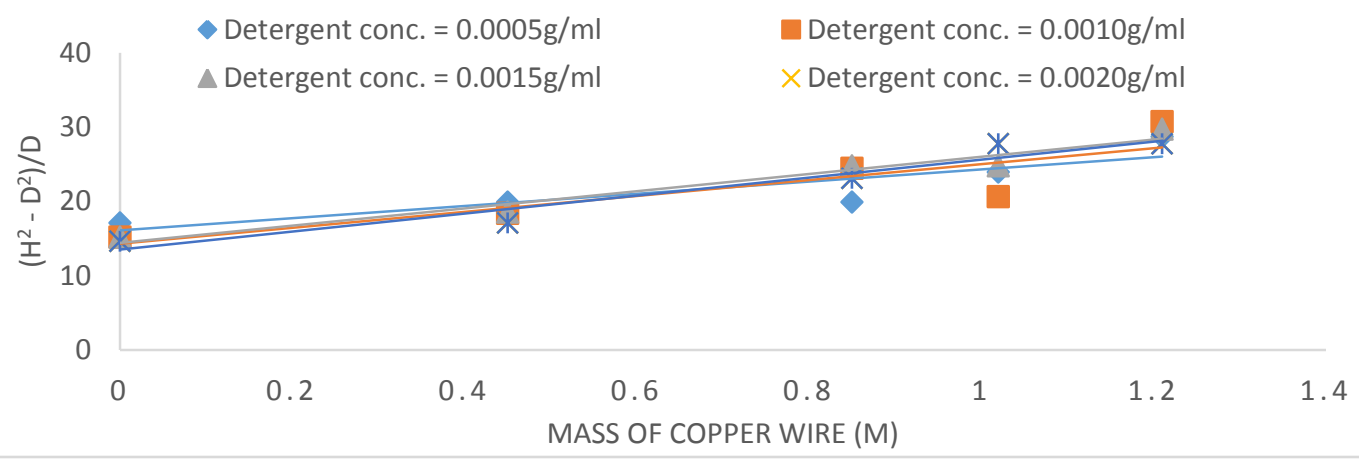

Figure 3b: Determination of CMC's of 50\% NaoH based Non-phosphate builder Detergent using different detergent concentrations

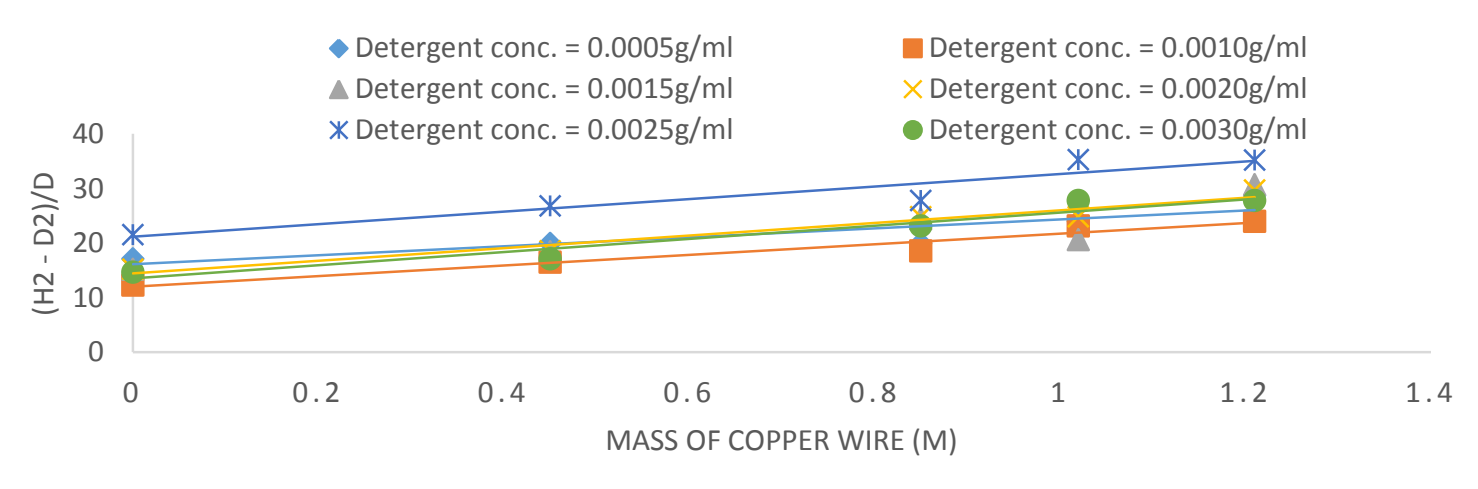

Figure 3c: Determination of CMC's of $75 \% \mathrm{NaoH}$ based Non-phosphate builder detergent using different detergent concentrations. 


\section{CONCLUSION}

From the results obtained in this work it can be concluded that the CMC's values of the nonphosphate detergent formulated using $75 \%$ and $50 \% \mathrm{NaOH}$ found to be $8.6685 \mathrm{mM}$ and 6.9348 $\mathrm{mM}$ respectively, conform well to that of the literature value of the range $(7-10 \mathrm{mM})$. While that of $25 \%$ based $\mathrm{NaOH}$ detergent found to be $5.2011 \mathrm{mM}$ does not agree with the values reported by Yunusa et al., (2009). The results also showed that, non-phosphate detergent prepared from Lokoja quartzite meets the requirement of good detergent and can replace phosphate detergent sold currently in the market which causes an eutrophication in our environment. Also, the CMC indicate amount of detergent needed to be used for a particular type of detergent. Hence, the more the CMC value the higher the quantity of detergent required.

\section{REFERENCES}

Barth, T. F. W. (2007). Quartzite Encyclopedia of Science \& Technology, 10th Edition. McGraw-Hill. 14: 722 Biophysical Journal 90(10): 310 - 317.

Campbell, H. A. (2008). Inorganic Components of Detergents Builders and other Additives: Kiwi Web, Chemistry and New Zealand.

Gregory, B., Victor, D., Daniel, F. and Jun, W. (2002). Colloid and Phenomena of Shampoo; Chemical Engineering Department State University of New York, Buffalo.

Gutti, B.(1999). Formulation of Sodium Silicate From Quartz; Unpublished B.sc Thesis Department of Chemical Engineering, AB.U, Zaria.

Held, P. (2014). Rapid Critical Micelle Concentration (CMC) Determination Using Fluorescence Polarization. Available online, http://www.biotek .com

/resources/articles/cmc_detrmination_u sing_fluorescence_polarization.html

Ibrahim, A B. (1995) Production of Sodium Silicate from Soda Ash; Unpublished B.sc Thesis, Department of Chemical Engineering, AB.U, Zaria.
James, A.K.(1992). Riegel's Handbook of Industrial Chemistry, 9th ed. Chapman and Hall Inc., New York.

Konyehi, U. E. (2008). Production of Biodegradable Detergent From Neem Seed Oil; Unpublished B.sc Project, Department of Chemical Engineering, A.B.U, Zaria.

Keshwani, A., Malhotra, B. and Kharkwal, $\mathrm{H}$. (2015). Natural Polymer Based Detergents for Stain Removal, World Journal Of Pharmacy And Pharmaceutical Sciences Vol. 4,:04,Pp 490-491. Amity Institute of Phytomedicine \& Phytochemistry and Coordinator for Amity Center for Carbohydrate Research Amity University, Noida.

Thomas, C. K., Andreas, E. and Harve-W.R. (2006) A Novel Method for Detergent Concentration Determination. Biophysical Journal. 90(10): 310-317.

Tschapek, B., Smits, S.H.J. and Schmitt, L. (2015). Analyzing the PhysicoChemical Parameters of

Detergents and Detergent Mixtures. Advances in Chemical Engineering and Science, 5,328-337.

http://www.scirp.org/journal/aces

Yangxin, Y., Jin, Z. and Bayly A. E. (2008) Development of Surfactants and Builders in Detergent Formulations Chinese Journal of Chemical Engineering, 16(4) 517-527

Yunusa, S., Mohammed-Dabo I.A and Ahmed, A.S. (2009a). Formulation of Biodegradable Synthetic Detergent Using A Non Phosphate Builder From Lokoja Quartzite, Unpublished M.sc Thesis, Department of Chemical Engineering, A.B.U, Zaria.

Yunusa, S., Mohammed I.A. and Ahmed, A.S. (2009b). Synthesis of Sodium Metasilicate from Lokoja Quartzite for Non- phosphate Detergent formulation, Chemclass Journal, 6:052-057, 52-57. 